\title{
LETTER
}

\section{Analysis of the electrolytic precipitation rate of calcite}

\author{
Norio YANAGISAWA* and Takahiro MATSUMURA ${ }^{* *}$ \\ *Institute for Geo-Resources and Environment, National Institute of \\ Advanced Industrial Science and Technology, Tsukuba 305-8569, Japan \\ ** REIKEN Co. Ltd., Moriya 302-0034, Japan
}

\begin{abstract}
A high-frequency electrolysis method was used to reduce the calcium in circulating water by precipitating $\mathrm{CaCO}_{3}$ on the electrodes. The oxidation-reduction potential, $\mathrm{pH}$, and chemical composition were measured during the precipitation of the $\mathrm{CaCO}_{3}$. The calcite precipitated on the electrode cover. The concentration of calcium ions in the solution decreased under reducing conditions, and the precipitation rate of calcite depended on the pH. For initial $\mathrm{Ca}$ and $\mathrm{HCO}_{3}$ concentrations of $200 \mathrm{ppm}$, the maximum precipitation rate of $\mathrm{CaCO}_{3}$ was 2.4 $\mathrm{mg} / \mathrm{m}^{2} / \mathrm{s}$ at $\mathrm{pH}=6.8$, and the precipitation rate decreased linearly as the $\mathrm{pH}$ decreased to $\mathrm{pH}=4.6$. The precipitation rate depended on the initial concentrations of calcium and $\mathrm{HCO}_{3}$, rather than being regulated by the initial $\mathrm{pH}$ using citric acid.
\end{abstract}

Keywords: Calcite, Electrolysis process, Precipitation rate, $\mathrm{pH}, \mathrm{ORP}$

\section{INTRODUCTION}

Calcium carbonate (calcite or aragonite) is a common mineral found in sedimentary rock, ore deposits, and fossils. There have been many examinations of water-rock interactions involving $\mathrm{CaCO}_{3}$, as summarized in Morse (1983). On the other hand, $\mathrm{CaCO}_{3}$ frequently precipitates in pipes as scale in hydraulic systems that are subject to changes in temperature, such as in geothermal power plants, hot springs, and the cooling towers of factories. Because the precipitation of scale in pipes decreases the heat-transfer performance and prevents water flow, much research has been carried out to prevent the precipitation of scale, and methods have been developed to prevent the precipitation of scale by using chemicals and electrolysis (Gabrielli et al., 1999; Morizot et al., 1999; Neville and Morizot, 2000; Rinat et al., 2005).

The concept of the electrolysis methods is as follows. The concentration of $\mathrm{Ca}$ and $\mathrm{HCO}_{3}$ ions is reduced by the forced precipitation of $\mathrm{CaCO}_{3}$ on the electrodes, which prevents the precipitation of $\mathrm{CaCO}_{3}$ in other sections of the pipeline.

In this study, we have clarified the details of the mechanism of $\mathrm{CaCO}_{3}$ precipitation from changes in the chemical properties of aqueous solutions using an electrolysis method, and we have determined the dependence of the precipitation rate on factors such as the ratio of the

doi:10.2465/jmps.060620a

N. Yanagisawa,n-yanagisawa@aist.go.jp Corresponding author
$\mathrm{Ca}$ and $\mathrm{HCO}_{3}$ ion concentrations and the $\mathrm{pH}$.

\section{EXPERIMENTAL}

High-frequency electrolysis experiments were carried out using a Dynakleen-D150T electrolysis system (Reiken Inc., Japan). The Dynakleen-D150T system consists of a control unit and an electrode unit with three electrodes. The electrode is $50 \mathrm{~mm}$ wide and $200 \mathrm{~mm}$ high, with many holes, and has a cylindrical electrode cover that is $130 \mathrm{~mm}$ in diameter and $220 \mathrm{~mm}$ high and also has many holes, as shown in Figure 1. The control unit provides a high-frequency current up to $30 \mathrm{kHz}$ to the three electrodes, and the precipitation of scale on the electrodes is prevented by periodically altering the polarity of the three electrodes. Then, any scale precipitated on only an electrode cover that surrounds the electrodes.

In this work, the Dynakleen-D150T system was placed in a 50-liter water tank and the measuring electrodes used to sense the $\mathrm{pH}$, electrical conductivity (EC), water temperature, and oxidation-reduction potential (ORP) were also immersed in the water tank, as shown in Figure 1. The measuring electrodes were connected to a $\mathrm{PC}$, and the $\mathrm{pH}, \mathrm{EC}$, and ORP data were continuously acquired. The $\mathrm{pH}$ was measured at a distance of $10 \mathrm{~mm}$ from the electrode cover on the surface of the water tank. The solutions were sampled from two locations: one near the electrode cover and the other on the surface of the experimental water tank. The $\mathrm{pH}$ and calcium ion concen- 


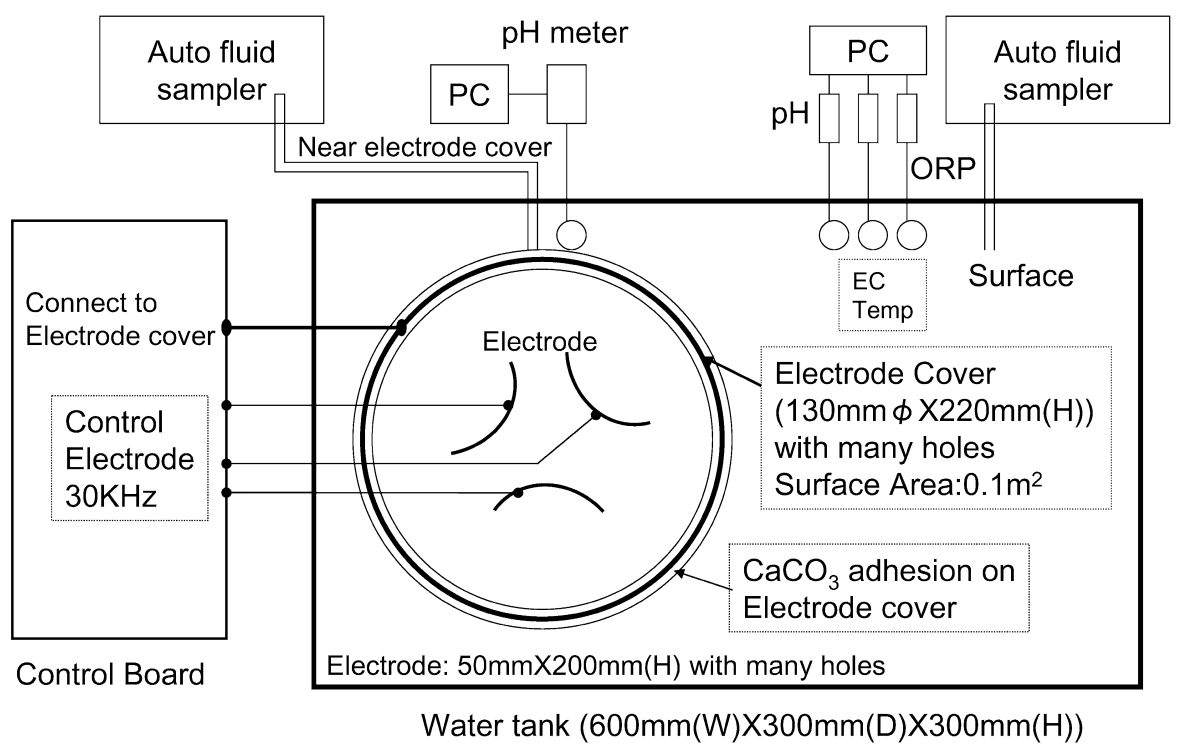

Figure 1. The Dynakleen-D150T experimental system.

tration were measured to confirm the $\mathrm{pH}$ distribution in the experimental water tank.

An experimental solution consisting of dissolved calcium lactate and sodium hydrogen carbonate in distilled water was used for the $\mathrm{Ca}$ and $\mathrm{HCO}_{3}$ ions, respectively. The samples were periodically collected to measure the $\mathrm{Ca}$ and $\mathrm{HCO}_{3}$ ion concentrations using an autosampler at $1.5 \mathrm{~h}$ intervals. The first experiment was carried out with an initial $\mathrm{Ca}$ concentration and $\mathrm{HCO}_{3}$ ion concentration of $200 \mathrm{ppm}$. In subsequent experiments, the initial $\mathrm{pH}$ was regulated with citric acid and the concentration of the $\mathrm{Ca}$ and $\mathrm{HCO}_{3}$ ions was varied within the range 100-300 ppm. The electric power supplied to the electrode had a mean voltage of $15 \mathrm{~V}$ and a current of 1.6 A. During the experiments, the water temperature was maintained at a constant temperature of $20^{\circ} \mathrm{C}$.

The $\mathrm{HCO}_{3}$ ion concentration in the solutions was measured using the $\mathrm{H}_{2} \mathrm{SO}_{4}$ titration method, and the calcium ion concentration was determined using ion chromatography. We calculated the $\mathrm{CaCO}_{3}$ precipitation rate using the change in $\mathrm{Ca}$ ion concentration in the solution during continuous sampling of two samples and from the $0.1 \mathrm{~m}^{2}$ surface area of the electrode cover. We compared the $\mathrm{CaCO}_{3}$ precipitation rate with the mean $\mathrm{pH}$ value during sampling.

\section{RESULTS AND DISCUSSION}

\section{Chemical changes in the solutions}

Figure 2 shows the changes in the ORP, $\mathrm{pH}$, and the concentration of $\mathrm{Ca}$ and $\mathrm{HCO}_{3}$ ions from the initial experimental period to a period of $72 \mathrm{~h}$, with the initial $\mathrm{Ca}$ and
$\mathrm{HCO}_{3}$ ion concentrations set at $200 \mathrm{ppm}$ each. First, the ORP value decreased rapidly after the commencement of the experiment, and reached $0 \mathrm{mV}$ after about $20 \mathrm{~min}$. It reached the minimum reduced value of $-250 \mathrm{mV}$ after approximately $3 \mathrm{~h}$. During this period, the $\mathrm{pH}$ also began to change: foam developed from the electrodes, and the $\mathrm{Ca}$ and $\mathrm{HCO}_{3}$ ion concentrations began to decrease. This shows that the $\mathrm{Ca}$ and $\mathrm{HCO}_{3}$ ions reacted as the solution entered the reduced state, and that $\mathrm{CaCO}_{3}$ precipitated as scale. The precipitation of white calcite scale on the electrode cover was observed.

The ORP value increased slightly, reaching zero after a period of $30 \mathrm{~h}$. During this period, the $\mathrm{pH}$ decreased to $\mathrm{pH}=4.8$, and the $\mathrm{HCO}_{3}$ ion concentration decreased to 40 ppm and the $\mathrm{Ca}$ ion concentration decreased to $100 \mathrm{ppm}$. Subsequently, these values reached a virtually constant level. We concluded that the precipitation rate of the scale had declined after an experimental period of $30 \mathrm{~h}$. About $13 \mathrm{~g}$ of white scale had adhered to the electrode cover, and this was identified as calcite from $\mathrm{X}$-ray powder diffraction data.

\section{Mechanism of the precipitation of scale}

The electron transfer due to the transfer of current is as follows:

$$
\begin{aligned}
& \text { Anode (+) side: } 2 \mathrm{H}_{2} \mathrm{O} \rightarrow 4 \mathrm{H}^{+}+4 \mathrm{e}^{-}+\mathrm{O}_{2} \\
& \text { Cathode (-) side: } 4 \mathrm{H}_{2} \mathrm{O}+4 \mathrm{e}^{-} \rightarrow 4 \mathrm{OH}^{-}+2 \mathrm{H}_{2} .
\end{aligned}
$$

The precipitation of $\mathrm{CaCO}_{3}$ on the electrode cover in contact with cathode was confirmed in our experiments. The precipitation reaction is represented by the following 
(1)

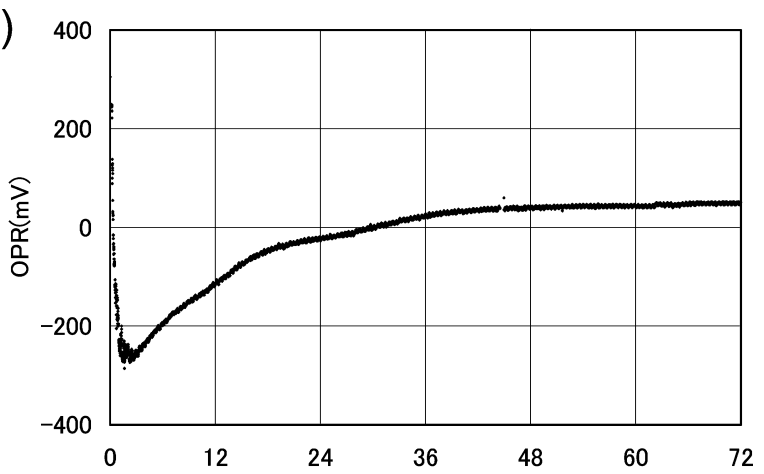

(2)

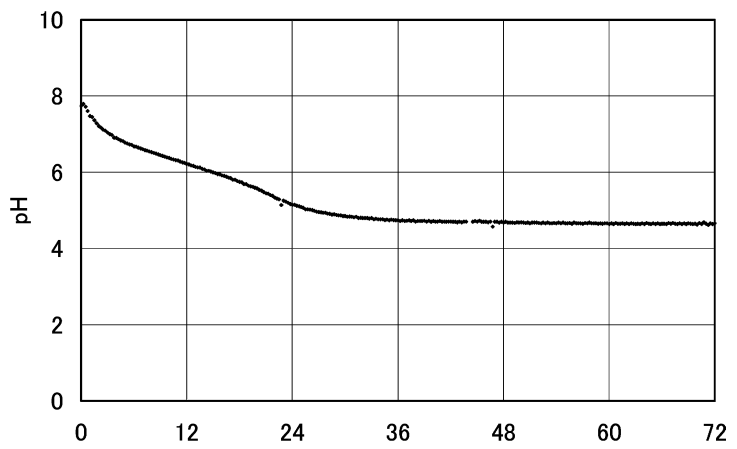

(3)

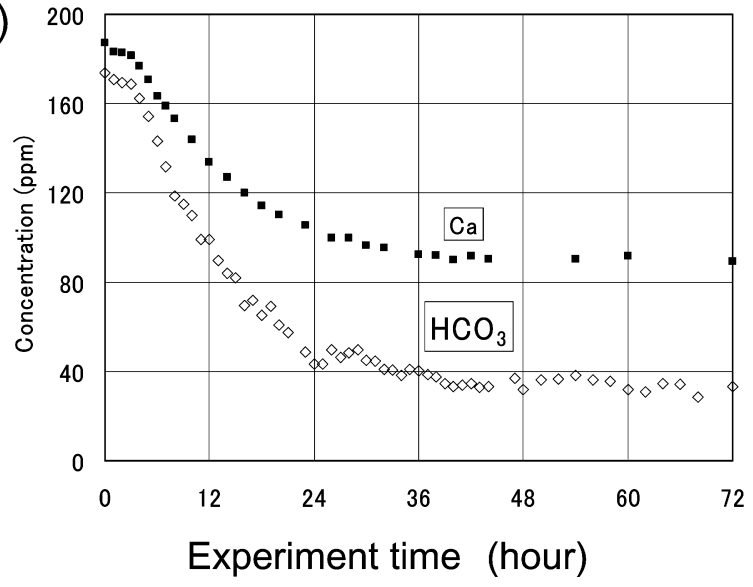

Figure 2. (1) $\mathrm{ORP}$, (2) $\mathrm{pH}$, and (3) $\mathrm{Ca}$ and $\mathrm{HCO}_{3}$ ion concentrations in an experiment with initial $\mathrm{HCO}_{3}$ and $\mathrm{Ca}$ ion concentrations of $200 \mathrm{ppm}$.

equation:

$$
\mathrm{Ca}^{2+}+\mathrm{HCO}_{3}^{-}+\mathrm{OH}^{-} \rightarrow \mathrm{CaCO}_{3}+\mathrm{H}_{2} \mathrm{O}
$$

Consequently, the deposition of $\mathrm{CaCO}_{3}$ is facilitated by the higher concentration of $\mathrm{Ca}, \mathrm{HCO}_{3}$ and $\mathrm{OH}^{-}$ions.

The $\mathrm{pH}$ near the electrode cover increased rapidly immediately after the transmission of an electric current and decreased rapidly after a period of $1 \mathrm{~h}$, showing a similar value to that on the surface of the water tank, as shown in Figure 3. The $\mathrm{Ca}$ ion concentration near the electrode cover usually exceeded the concentration observed at other sites. This indicates that the deposition of

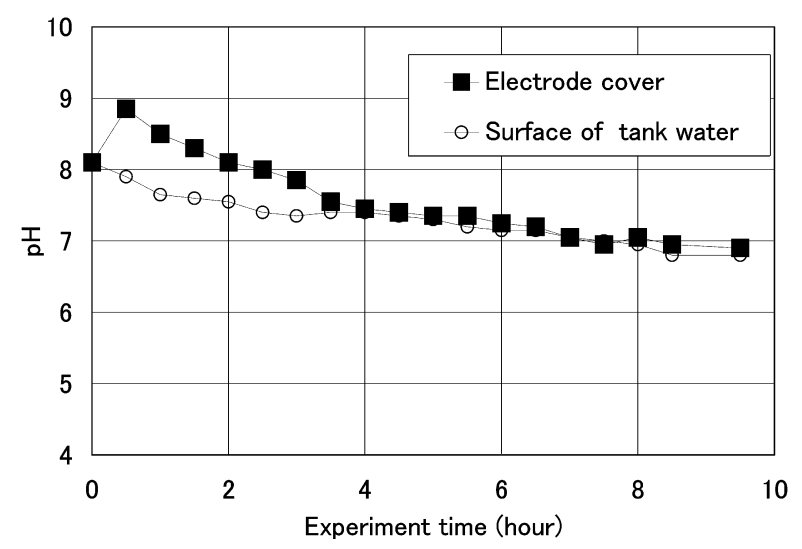

Figure 3. The $\mathrm{pH}$ distribution in an aqueous solution.

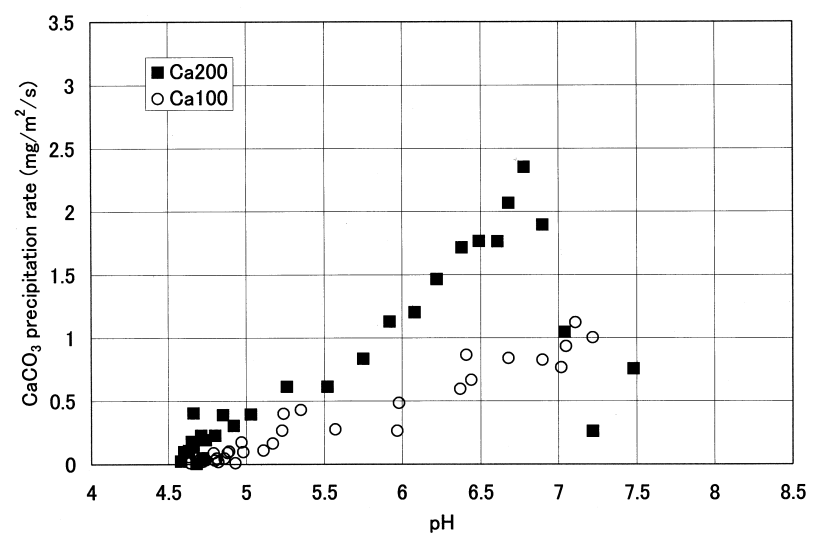

Figure 4. The $\mathrm{pH}$ dependence of the calcite precipitation rate (for equal concentrations of $\mathrm{Ca}$ and $\mathrm{HCO}_{3}$ ions).

$\mathrm{CaCO}_{3}$ readily occurs near the electrode cover. The $\mathrm{OH}^{-}$ ions are then used up as the deposition of $\mathrm{CaCO}_{3}$ proceeds, and the $\mathrm{pH}$ of the solution decreases, since the $\mathrm{H}^{+}$ ions generated from the anode remain in solution.

We did not observe any precipitation of $\mathrm{CaCO}_{3}$ in the water tank except that observed on the electrode cover. In addition, in a test where no electrical power was supplied, we did not observe any precipitation of $\mathrm{CaCO}_{3}$ in the water tank and the concentration of $\mathrm{Ca}$ ions was constant. We supposed that $\mathrm{CaCO}_{3}$ nucleation and precipitation occurred only on the electrode cover in this experiment.

\section{Dependence of $\mathrm{pH}$ on the $\mathrm{CaCO}_{3}$ precipitation rate}

We observed delayed changes in the calcium concentration in the solution as the $\mathrm{pH}$ decreased. Thus, from the changes in calcium ion concentration, we calculated the precipitation rate of $\mathrm{CaCO}_{3}$ per square meter of electrode cover, and determined the relationship between the precipitation rate and the $\mathrm{pH}$.

Figure 4 shows the relationship between the $\mathrm{pH}$ and 


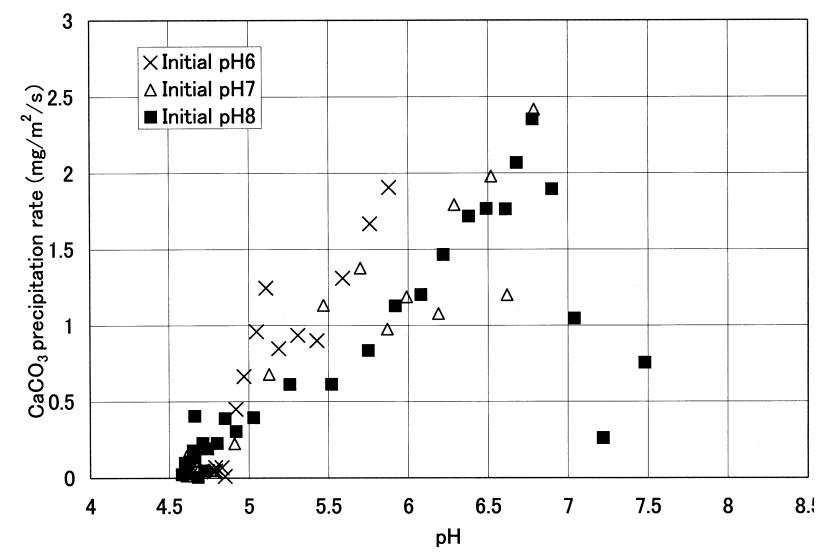

Figure 5. The $\mathrm{pH}$ dependence of the calcite precipitation rate (regulation of the initial $\mathrm{pH}$ ).

the precipitation rate of the scale. At a calcium ion concentration of $200 \mathrm{ppm}$, the precipitation rate increased rapidly when the $\mathrm{pH}$ decreased from $\mathrm{pH} \sim 8$ to $\mathrm{pH}=6.8$, and reached $2.4 \mathrm{mg} / \mathrm{m}^{2} / \mathrm{s}$ at $\mathrm{pH}=6.8$. Thereafter, the precipitation rate decreased linearly with decreasing $\mathrm{pH}$, and it virtually ceased at $\mathrm{pH}=4.6$. Conversely, at a calcium ion concentration of $100 \mathrm{ppm}$, the precipitation rate was $1.1 \mathrm{mg} / \mathrm{m}^{2} / \mathrm{s}$ at $\mathrm{pH}=7.1$, which was half the rate observed when the calcium ion concentration was $200 \mathrm{ppm}$. The precipitation rate decreased linearly with decreasing $\mathrm{pH}$, but, in general, the precipitation rate was proportional to the calcium ion concentration and reached a value of zero at $\mathrm{pH}=4.6$, which is similar to the case where the calcium ion concentration was $200 \mathrm{ppm}$.

Figure 5 shows data from a comparative experiment, in which the initial concentration of calcium and $\mathrm{HCO}_{3}$ ions was $200 \mathrm{ppm}$, and the $\mathrm{pH}$ was set to $\mathrm{pH}=6,7$, and 8 using citric acid. The initial $\mathrm{pH}$ was $\mathrm{pH}=7$, and the precipitation rate was $2.4 \mathrm{mg} / \mathrm{m}^{2} / \mathrm{s}$ at $\mathrm{pH}=6.8$. Subsequently, the overall precipitation rate decreased linearly with decreasing $\mathrm{pH}$. A similar trend was observed when the initial $\mathrm{pH}$ was $\mathrm{pH}=8$. When the initial $\mathrm{pH}$ was $\mathrm{pH}=6$, the precipitation rate reached $1.9 \mathrm{mg} / \mathrm{m}^{2} / \mathrm{s}$ at $\mathrm{pH}=5.9$, and tended to show somewhat higher values compared with the precipitation rates for an initial $\mathrm{pH}$ of $\mathrm{pH}=7$ or 8 , but it decreased linearly and reached a value of zero near $\mathrm{pH}=4.8$. This indicates that the precipitation rate decreased linearly with decreasing $\mathrm{pH}$, even when the initial $\mathrm{pH}$ of the solution was altered. The precipitation rate reached zero in the $\mathrm{pH}$ range of $\mathrm{pH}=4.6-4.8$.

Figure 6 shows the relationship between the $\mathrm{pH}$ and the precipitation rate of the scale when the initial $\mathrm{HCO}_{3}$ concentration was set to 100,200 , and $300 \mathrm{ppm}$. At an $\mathrm{HCO}_{3}$ ion concentration of $100 \mathrm{ppm}$, the reaction was initiated at $\mathrm{pH}=8.5$, at which point the initial rate was $1.5 \mathrm{mg} / \mathrm{m}^{2} / \mathrm{s}$. The precipitation rate decreased linearly

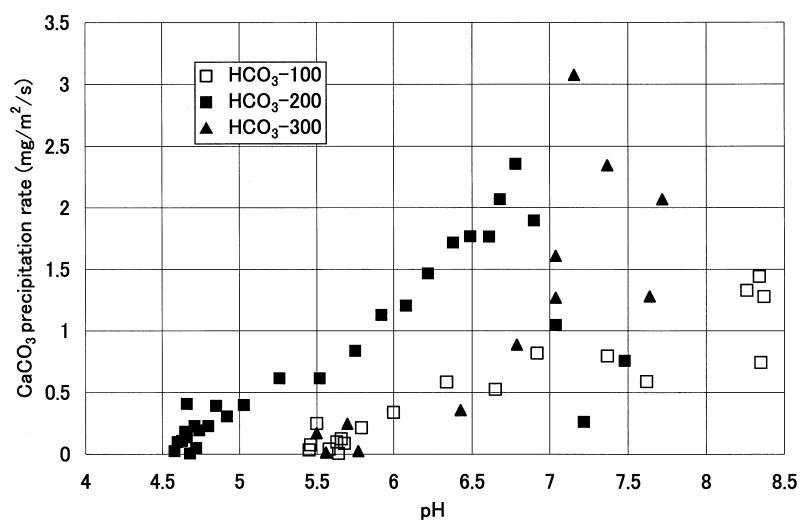

Figure 6. The $\mathrm{pH}$ dependence of the calcite precipitation rate (change in $\mathrm{HCO}_{3}$ ion concentration).

with decreasing $\mathrm{pH}$, and reached a value of zero at $\mathrm{pH} \sim$ 5.5. The precipitation rate increased in the range $\mathrm{pH}=7.7-$ 7.2 at an $\mathrm{HCO}_{3}$ ion concentration of $300 \mathrm{ppm}$ and exceeded $3.0 \mathrm{mg} / \mathrm{m}^{2} / \mathrm{s}$ at $\mathrm{pH}=7.2$, but the rate decreased rapidly with decreasing $\mathrm{pH}$ and reached a value of zero at $\mathrm{pH} \sim 5.5$.

In this way, the precipitation rate increased rapidly on initiation of the electrolytic current, and reached a peak at $\mathrm{pH} \sim 7$ with an initial $\mathrm{HCO}_{3}$ ion concentration of 200 $\mathrm{ppm}$, after which, the precipitation rate decreased in a linear manner. The precipitation rate depended on the initial concentration of calcium and $\mathrm{HCO}_{3}$ ions, rather than being regulated by the initial $\mathrm{pH}$ using citric acid. The precipitation rate for $\mathrm{Ca} / \mathrm{HCO}_{3}$ ratios that deviated from the ratio of 1:1 was lower than that when the initial concentrations were equal at the same $\mathrm{pH}$.

\section{CONCLUSIONS}

1. Calcium carbonate was precipitated on the electrode cover of the Dynakleen-D150T system from the following reaction:

$$
\mathrm{Ca}^{2+}+\mathrm{HCO}_{3}^{-}+\mathrm{OH}^{-} \rightarrow \mathrm{CaCO}_{3}+\mathrm{H}_{2} \mathrm{O} .
$$

The $\mathrm{pH}$ of the aqueous solution decreased as this reaction progressed. In addition, the $\mathrm{pH}$ in the vicinity of the electrode cover was higher than at other sites, and the calcium ion concentration was also confirmed to be higher.

2. With progressive precipitation of scale and decrease in $\mathrm{pH}$, the precipitation rate of the scale decreased linearly and was accompanied by a decrease in the $\mathrm{pH}$ to $\mathrm{pH}<7$, regardless of the initial $\mathrm{pH}$ and calcium and $\mathrm{HCO}_{3}$ ion concentrations. The precipitation rate depended on the initial concentrations of calcium and $\mathrm{HCO}_{3}$ ions, rather 
than being regulated by the initial $\mathrm{pH}$ using citric acid.

\section{ACKNOWLEDGMENTS}

We thank the Reiken Co. Ltd. for funding the experiments and for granting permission to publish this letter.

\section{REFERENCES}

Gabrielli, C., Maurin, G., Poindessous, G. and Rosset, R. (1999) Nucleation and growth of calcium carbonate by an electrochemical scaling process. Journal of Crystal Growth, 200, 236-250.

Morizot, A., Neville, A. and Hodgkiess, T. (1999) Studies of the deposition of $\mathrm{CaCO}_{3}$ on a stainless steel surface by a novel electrochemical technique. Journal of Crystal Growth, 198/
199, 738-743.

Morse, J.W. (1983) The kinetics of calcium carbonate dissolution and precipitation. In Reviews in Mineralogy. 11, Carbonate. pp. 394, Mineralogical Society of America, 227-264.

Neville, A. and Morizot, A.P. (2000) A combined bulk chemistry/ electrochemical approach to study the precipitation, deposition and inhibition of $\mathrm{CaCO}_{3}$. Chemical Engineering Science, 55, 4737-4743.

Rinat, J., Korin, E., Soifer, L. and Bettelheim, A. (2005) Electrocrystallization of calcium carbonate on carbon-based electrodes. Journal of Electroanalytical Chemistry, 575, 195-202.

Manuscript received June 20, 2006

Manuscript accepted August 10, 2006

Published online November 24, 2006

Manuscript handled by Motoharu Kawano 